\title{
Impact of Climate Change on Hydrologic Extremes in the Upper Basin of the Yellow River Basin of China
}

\author{
Jun Wang, ${ }^{1}$ Zhongmin Liang, ${ }^{1,2}$ Dong Wang, ${ }^{1}$ Tian Liu, ${ }^{1}$ and Jing Yang ${ }^{1}$ \\ ${ }^{1}$ College of Hydrology and Water Resources, Hohai University, Nanjing 210098, China \\ ${ }^{2}$ State Key Laboratory of Hydrology-Water Resources and Hydraulic Engineering, Hohai University, Nanjing 210098, China
}

Correspondence should be addressed to Zhongmin Liang; zmlianghhu@126.com

Received 16 October 2015; Revised 21 February 2016; Accepted 17 March 2016

Academic Editor: Jingfeng Wang

Copyright (C) 2016 Jun Wang et al. This is an open access article distributed under the Creative Commons Attribution License, which permits unrestricted use, distribution, and reproduction in any medium, provided the original work is properly cited.

To reveal the revolution law of hydrologic extremes in the next 50 years and analyze the impact of climate change on hydrologic extremes, the following main works were carried on: firstly, the long duration ( $15 \mathrm{~d}, 30 \mathrm{~d}$, and $60 \mathrm{~d})$ rainfall extremes according to observed time-series and forecast time-series by dynamical climate model product (BCC-CSM-1.1) were deduced, respectively, on the basis that the quantitative estimation of the impact of climate change on rainfall extremes was conducted; secondly, the SWAT model was used to deduce design flood with the input of design rainfall for the next 50 years. On this basis, quantitative estimation of the impact of climate change on long duration flood volume extremes was conducted. It indicates that (1) the value of long duration rainfall extremes for given probabilities (1\%, $2 \%, 5 \%$, and $10 \%)$ of the Tangnaihai basin will rise with slight increasing rate from $1 \%$ to $6 \%$ in the next 50 years and (2) long duration flood volume extremes of given probabilities of the Tangnaihai basin will rise with slight increasing rate from $1 \%$ to $6 \%$ in the next 50 years. The conclusions may provide technical supports for basin level planning of flood control and hydropower production.

\section{Introduction}

Climate change has affected many fields of nature and human society in recent years and has been one of the most attractive research fields. On the background, the estimation and simulation of the impact of climate change in the hydrology have been becoming a research topic. Many hydrologists [14], who have done research on the hydrological response to climate change and human activities, believe that anthropogenic global climate change and human activities have significantly affected hydrologic cycle and resulted in changes in the spatial and temporal distribution of water resources at both global and local scales. It is no doubt that the changes in the hydrological cycle will have serious impacts on ecological, social, and economic situations $[5,6]$ and bring us severe challenges. To respond to the climate change challenge, one of the most important tasks is to reveal influencing mechanism of hydrologic cycle by climate change and to predict the impact on corresponding fields. Many hydrologists have been working on it; for example, some studies have identified robust trends over some specific regions $[7,8]$. However, there are still many questions unclear and the research should be continued. With the development of society, the demand of scientificity of the basin level and national planning of flood control, hydropower production, agricultural irrigation, and ecosystem preservation are increasing; hence, projecting the future climate and assessing its probable impact on water resources are critical. Many studies on the impacts of climate change on hydrological regimes [9-11] have been conducted. In these studies, global climate models and hydrologic model were usually used to simulate the changes in hydrological regimes at watershed scales.

Most of the previous climate change impact assessment studies on hydrological processes of Yellow River watershed focused on the trend of hydrologic elements [12]. However, the assessment study on revolution law of the hydrologic extremes responding to climate change of Yellow River basin is hardly a blank. To reveal the revolution law of hydrologic extremes and assess the impact of climate change on hydrologic extremes in the upper Yellow River basin, 
the objectives of the paper include (1) evaluation of the impact of climate change on precipitation extremes of long duration $(15 \mathrm{~d}, 30 \mathrm{~d}$, and $60 \mathrm{~d})$ for given probabilities $(1 \%$, $2 \%, 5 \%$, and $10 \%)$; (2) evaluation of the impact of climate change on flood volume extremes of long duration (15 d, $30 \mathrm{~d}$, and $60 \mathrm{~d})$ for given probabilities $(1 \%, 2 \%, 5 \%$, and $10 \%)$, through hydrologic frequency analysis that deduce the design rainfall for the measured phase and the future by running distributed hydrological model (SWAT) with the input condition of design rainfall to deduce the flood volume extreme of different duration. The paper focuses on revealing the impact of climate change on the hydrologic extremes of the Tangnaihai basin which locates in the upstream of Yellow River; the main content is as follows: the methods applied to study the impact of climate change on hydrologic extreme, including hydrologic frequency analysis method, the bias correction method, and the hydrological model, are described in Section 2. The study area and available data are then introduced in the Section 3. The results of impact of climate change on hydrologic extremes are presented in Section 4. The conclusions are finally remarked in Section 5.

\section{Methodologies}

2.1. Frequency Analysis of Precipitation Extremes. To reveal the statistical law of the hydrologic extremes, hydrologic time series analysis and modeling are an effective approach. Obviously, hydrologic frequency analysis is one of most popular approaches which are based on time series to analyze the law of hydrologic extremes $[13,14]$. The key of hydrologic frequency analysis is to determine the probability distribution of extreme. As we known, there are many functions, including extreme value distribution (Gumbel distribution), generalized extreme value distribution (GEV), log-normal distribution (L-N), the Pearson type III distribution (P-III), and the logarithmic Pierre Johnson III distribution, that could be used as the probability distribution of hydrologic extremes.

In China, Liang [15] showed that the P-III distribution is suitable for description of the statistical law of hydrologic extremes, such as annual maximum rainfall, annual maximum flood peak discharge, and annual maximum flood volume of different duration, based on the application experiences. Therefore, the Pearson type III (P-III) curve has been used for the hydrologic frequency analysis in China.

The P-III curve is known as the $\gamma$ distribution mathematically (Gamma distribution with three parameters). Its probability density function is expressed as follows:

$$
\begin{aligned}
& f(x)=\frac{\beta^{\alpha}}{\Gamma(\alpha)}\left(x-a_{0}\right)^{\alpha-1} e^{-\beta\left(x-a_{0}\right)}, \\
& x>a_{0}, \alpha>0, \beta>0,
\end{aligned}
$$

where $a_{0}, \beta$, and $\alpha$ denote the position, scale, and shape parameters of the distribution, respectively. The relation of these parameters and three moments $(E x, C v$, and $C s)$ can be expressed as follows:

$$
\begin{aligned}
& a_{0}=E x\left(1-\frac{2 C v}{C s}\right), \\
& \alpha=\frac{4}{C s^{2}}, \\
& \beta=\frac{2}{E x C v C s},
\end{aligned}
$$

where Ex denotes the mean of hydrologic extreme time series; $C v$ is the variance of hydrologic extreme time series; and $C s$ is the variable coefficient of hydrologic extreme time series.

Hydrologic frequency analysis and calculation are to ascertain the random variable $x$ corresponding to the specified frequency $p$, which can be obtained by the distribution function defined by transcendental probability:

$$
p=F\left(x_{p}\right)=P\left(x \geq x_{p}\right)=\int_{x_{p}}^{\infty} f(x) d x .
$$

To simplify the integration solution of (3), the variables of the Pearson type III distribution can be obtained by standard transformation of variable $x$ :

$$
\Phi=\frac{x-E x}{E x C v}
$$

where $\Phi$ is known as coefficient of mean deviation. Then the integral operation of $x$ is

$$
\begin{aligned}
p & =P\left(\Phi \geq \Phi_{p}\right)=\int_{\Phi_{p}}^{\infty} g(\Phi, \alpha) d \Phi \\
& =\frac{\alpha^{\alpha / 2}}{\Gamma(\alpha)} \int_{\Phi_{p}}^{\infty}(\Phi+\sqrt{\alpha})^{\alpha-1} e^{-\sqrt{\alpha}(\Phi+\sqrt{\alpha})} d \Phi,
\end{aligned}
$$

where the integrand $g(\Phi, \alpha)$ contains only one unknown parameter $\alpha$ or $C s\left(\alpha=4 / C s^{2}\right)$. According to hydrologic customary, the relationship of $C s, p$, and $\Phi_{p}$ is tabulated in advance, namely, $\Phi$-value hydrographic table. The corresponding $x_{p}$ can be obtained through the inverse transform of (4) which is expressed as follows:

$$
x_{p}=\operatorname{Ex}\left(1+C v \Phi_{p}\right) .
$$

2.2. Frequency Analysis of Flood Volume Extremes with Different Durations. Approach to deduce flood volume extremes with different durations can be divided into two types according to the data condition [16]: one is the so-called direct method when the length of observed discharge time series is relatively long. According to observed maximum discharge time series, the flood volume extremes of different duration with a certain probability can be deduced by hydrologic frequency analysis as shown in Section 2.1; the other one is the so-called indirect method when the length of observed discharge time series is relatively short or there is no observed discharge data. According to observed precipitation 
data, the precipitation extremes of different duration with a certain probability can be deduced by hydrologic frequency analysis firstly, on the basis that the flood volume extremes with different durations of corresponding probability can be deduced by rainfall-runoff model on the hypothesis that rainfall with given frequency could generate the flood with the same frequency.

There are many hydrologic models for rainfall-runoff simulation; in the paper, the SWAT model which is famous as distributed hydrologic model and widely applied all over the world was adopted to deduce the flood volume.

2.3. Hydrologic Model: SWAT. To evaluate quantitatively the impact of climate change on the flood extreme, hydrologic model is needed to simulate the flood. There are many rainfall-runoff models such as Xin'anjiang model, TOPMODEL, and VIC model. In the paper, SWAT model was selected because of its powerful hydrological process simulation capabilities. Known as a famous distributed hydrologic model, SWAT model is a continuous-time, semidistributed, process-based river basin or watershed scale model. SWAT model was developed to predict the impact of land management practices on water, sediment, and chemical yields in agricultural watersheds with varying soils, land use, and management conditions over long period of time $[17,18]$. Comparing with other hydrologic models, SWAT has two outstanding features. One is the use of Hydrologic Response Unit (HRU), which is divided according to land use, soil distribution, and slope type, as the calculation unit [19]. SWAT divides a watershed into subbasins. Each subbasin is connected through a stream channel and further each subbasin is divided into HRUs. SWAT simulates hydrology and sediment at the HRU level. Water and sediment from each HRU are summarized in each subbasin and then routed through the stream network to the watershed outlet $[18,20]$. The other one is the simulation of surface runoff by using the modified SCS curve number which is deduced based on land use and soil type of watershed [21].

2.4. Bias Correction of Climate Model. Systematic errors of climate models may lead to unrealistic hydrological simulations of river flow $[22,23]$; thus, bias correction methods must be implemented to correct the climate product before application and analysis. For adjusting climate model product, the linear scaling, local intensity scaling, power transformation, variance scaling, distribution transfer, and the delta-change approaches are the commonly used bias correction methods [24]. Bias correction methods are based on the assumption that the same correction algorithm applies to both current and future climate conditions. In the study, linear scaling method was employed to correct the daily precipitation and monthly precipitation of climate model.

Based on the precipitation simulated by climate model and the corresponding measured precipitation, correction coefficients of each month were calculated. The precipitation predicted by climate model was modified on the basis of correction coefficients scaling monthly precipitation data predicted by the model. The correction coefficient can be calculated by

$$
\lambda_{i}=\frac{\overline{P_{i}^{o}}}{\overline{P_{i}}}
$$

where $\lambda_{i}$ is the correction coefficient of the $i$ th month, $\overline{P_{i}^{o}}$ is the measured monthly mean precipitation of the $i$ th month of reference period, and $\overline{P_{i}}$ is the monthly mean precipitation simulated by the climate model of the $i$ th month of reference period.

\section{Study Area and Base Data}

3.1. Study Area. Tangnaihai basin with a drainage area of $122,000 \mathrm{~km}^{2}$ is located in the upstream of Yellow River in the western China, accounting for $15 \%$ of that of the Yellow River basin. Annual average runoff amount at the Tangnaihai cross section is $205.2 \times 10^{8} \mathrm{~m}^{3}$, accounting for $40 \%$ of annual mean runoff amount of Yellow River basin. It is a semihumid region with good vegetation and less human activity. In the study, nine meteorological stations and seven hydrologic stations are involved. Figure 1 shows the location of the study area and gauging stations distribution.

3.2. Base Data. Five types of data, including hydrometeorology data, DEM, land use, soil distribution, and climate model data, are involved in the study. The details of data are as follows.

3.2.1. Hydrometeorology Data. Hydrometeorology data used in the study is the information of the elements influencing hydrologic cycle, such as rainfall, evaporation, runoff, and temperature. The basic data mainly comes from two sources: one is the 9 meteorological stations mentioned above which can provide precipitation, temperature, wind speed, solar radiation, relative humidity, and some other meteorological data; the other one is 7 hydrologic stations shown in Figure 2 which can provide precipitation, discharge, and evaporation. The length of the data series ranging from 1960 to 2012 is 53 years.

3.2.2. DEM. DEM is the basis for generating digital watershed system of Tangnaihai basin; in the paper, SRTM (Shuttle Radar Topography Mission) DEM with $90 \mathrm{~m} \times 90 \mathrm{~m}$ resolution ratio, which is produced by NASA and NIMA, was utilized.

3.2.3. Land Use and Soil Distribution. Land use and soil distribution which are used to divide the whole basin into different HRUs are the basis of runoff yield calculation of SWAT model and play an important role in hydrologic model structure. In the paper, the dataset of WESTDC_Land_Cover_V.1.0 investigated by Chinese Academy of Sciences with the scale of $1: 100,000$ and the soil distribution data provided by Institute of Soil Science from the second national land survey were chosen to build SWAT model. 

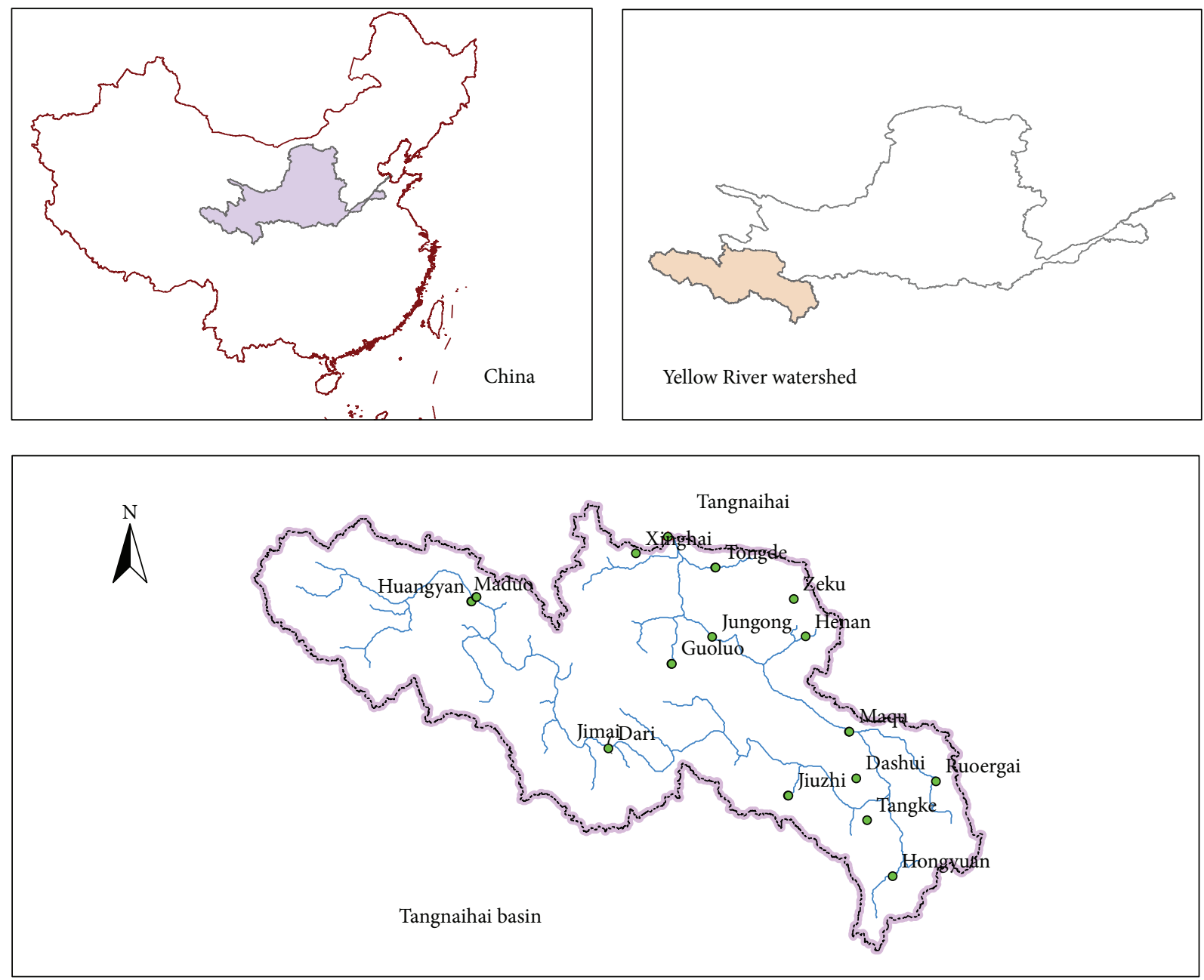

- Station

- Outlet

- River

Figure 1: Location and hydrometeorological stations of the study area.

3.2.4. Climate Model Product. There are many dynamical climate model products under different climate scenarios and hypothesis released by IPCC AR5. It is unnecessary and unrealistic to analyze every climate model product in this study; one certain climate model product should be focused on instead. In this paper, several climate model products which suit the region where China locates were selected firstly. On the basis, the accuracy of predicted precipitation of the climate model products was analyzed, and the climate model product called BCC-CSM-1.1 is of good prediction effect and chosen as the basic data for conducting the evolution law of hydrologic extreme value of the upstream region of Yellow River basin. BCC-CSM-1.1 is provided by Beijing Climate Center of China Meteorological Administration with a space resolution $1.125^{\circ} \times 1.125^{\circ}$.

3.3. Durations of Hydrologic Selection. The longer durations $(15 \mathrm{~d}, 30 \mathrm{~d}$, and $60 \mathrm{~d})$, instead of shorter durations (1 d,
$3 \mathrm{~d}, 5 \mathrm{~d}$, or $7 \mathrm{~d}$ ), of hydrologic extreme were focused on in the paper. There are two reasons. First, flood volume of longer duration plays a control role in flood control the consequences for larger basin. The Tangnaihai basin is a large basin with drainage area of $122,000 \mathrm{~km}^{2}$ and its basin flow concentration time is $>15 \mathrm{~d}$. From this view, research on flood extreme of longer durations might be more meaningful for Tangnaihai basin; second, there are many reservoirs built or planned to be built, and flood volume of shorter durations will be influenced greatly by reservoir regulation, while that of longer durations will be maintain natural. Therefore, the time series of flood volume of shorter durations ( $1 \mathrm{~d}, 3 \mathrm{~d}, 5 \mathrm{~d}$, or $7 \mathrm{~d}$ ) are inconsistent and not suitable for frequency analysis of which theory is built on consistency of time series. In conclusion, evaluation the impact of climate change on hydrologic extreme of longer durations (15 d, $30 \mathrm{~d}$, and $60 \mathrm{~d}$ ) would be more meaningful and applicative. 


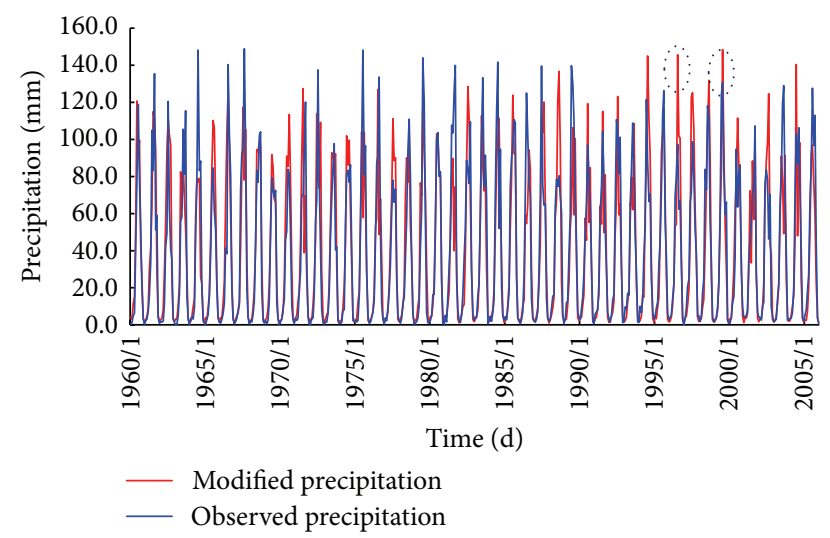

Figure 2: Results of precipitation correction (1960-2006) of the Tangnaihai basin.

\section{Results and Discussion}

To reveal the revolution law of hydrologic extremes of the Tangnaihai basin, the observed hydrologic time series from 1960 to 2010 and the predicted precipitation time series from 2011 to 2060 were used. In this paper, the years from 1960 to 2010 are defined as the measured phase while the years from 2011 to 2060 are denoted as the next 50 years.

4.1. Bias Correction of BCC-CSM-1.1. To correct systematic errors of simulated precipitation of BCC-CSM-1.1 of the Tangnaihai basin, the correction model was built with linear regression relationship between observed and simulated precipitation in synchronized period. In the paper, the precipitation time series range from 1960 to 2006. Figure 2 shows the correction results.

According to the correction results, it is found that there was large correction error in the months of low-water seasons as the position of black circle shows in Figure 2, while the rest of correction results were of high accuracy. Since the paper focused on studying the precipitation extreme, the error of low-water months will have little effect. Therefore, the correction model built can be used to correct the simulation precipitation of BCC-CSM-1.1 of the Tangnaihai basin.

\subsection{Impact of Climate Change on Rainfall Extremes}

4.2.1. Rainfall Extremes of Different Duration Analysis Based on Observed Data. The statistical law of rainfall extremes in the measured phase should be revealed first for uncovering the influences of climate on rainfall extremes. In the paper, the series of maximum value of annual rainfall extremes in different durations, such as 15 days, 30 days, and 60 days, was calculated by observed data and utilized to invest the statistical law of rainfall extremes. As mentioned above, the PIII distribution is suited for frequency analysis of hydrologic extremes in China. Therefore, the design rainfall of different durations $(15 \mathrm{~d}, 30 \mathrm{~d}$, and $60 \mathrm{~d})$ of any probability can be deduced. Figure 3 shows the frequency curve of rainfall of different durations fitting by observed data. The parameters
TABLE 1: Results of parameters estimation of P-III distribution for the measured phase.

\begin{tabular}{lccc}
\hline Duration $(\mathrm{d})$ & Mean $(\mathrm{mm})$ & $C v$ & $C s / \mathrm{Cv}$ \\
\hline 15 & 80 & 0.20 & 3.5 \\
30 & 130 & 0.19 & 3.5 \\
60 & 215 & 0.17 & 3.5 \\
\hline
\end{tabular}

TABLE 2: Design rainfall in different durations of different return periods for the measured phase $(\mathrm{mm})$.

\begin{tabular}{lcccc}
\hline \multirow{2}{*}{ Duration (d) } & \multicolumn{4}{c}{ Return period (a) } \\
& 100 & 50 & 20 & 10 \\
\hline 15 & 126 & 119 & 110 & 102 \\
30 & 200 & 190 & 175 & 163 \\
60 & 316 & 302 & 281 & 264 \\
\hline
\end{tabular}

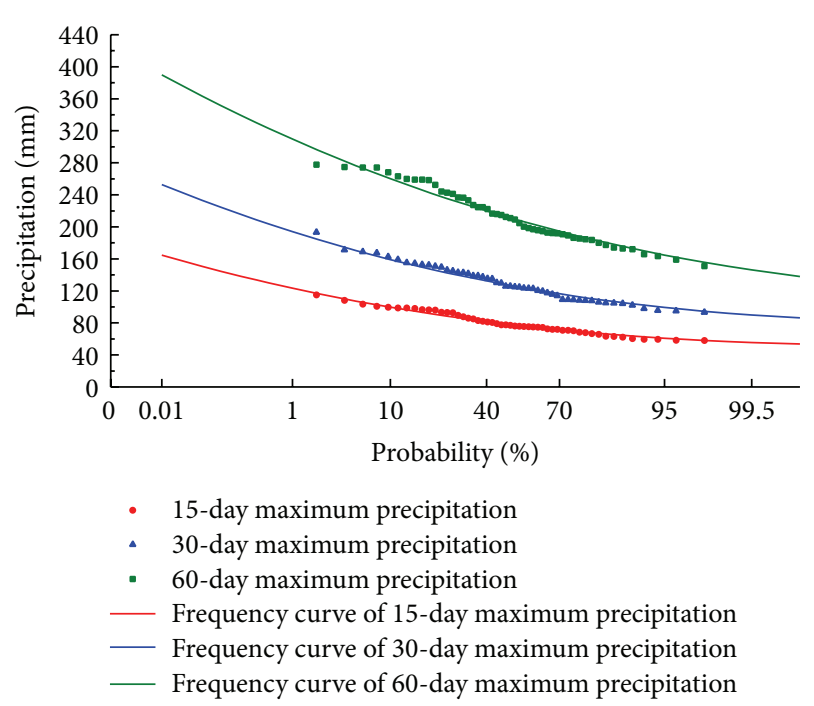

FIGURE 3: Frequency curve-fitting of rainfall extreme in different durations for the measured phase of Tangnaihai basin.

estimation results of P-III distribution are listed in Table 1 while the design values for given probabilities are listed in Table 2.

4.2.2. Analysis of Rainfall Extremes of Different Durations with BCC-CSM-1.1. Time series of rainfall extremes in different durations ( $15 \mathrm{~d}, 30 \mathrm{~d}$, and $60 \mathrm{~d})$ in the next 50 years from 2011 to 2060 can be extracted according to the correction results of BCC-CSM-1.1. Similar to frequency analysis in the measured phase, the parameters estimation of P-III distribution and design value of different durations for next 50 years can be obtained. The corresponding frequency curves are shown in Figure 4, and the parameters estimation results are listed in Table 3 while the design values of several given probabilities are listed in Table 4. 
TABLE 3: Results of parameters estimation of P-III distribution for the next 50 years.

\begin{tabular}{lccc}
\hline Duration $(\mathrm{d})$ & Mean $(\mathrm{mm})$ & $C v$ & $C s / C v$ \\
\hline 15 & 84 & 0.18 & 3.5 \\
30 & 137 & 0.17 & 3.5 \\
60 & 231 & 0.15 & 3.5 \\
\hline
\end{tabular}

TABLE 4: Design rainfall in different durations of different return period for the next 50 years $(\mathrm{mm})$.

\begin{tabular}{lcccc}
\hline \multirow{2}{*}{ Duration (d) } & \multicolumn{4}{c}{ Return period (a) } \\
& 100 & 50 & 20 & 10 \\
\hline 15 & 128 & 122 & 113 & 105 \\
30 & 201 & 192 & 179 & 168 \\
60 & 332 & 318 & 297 & 280 \\
\hline
\end{tabular}

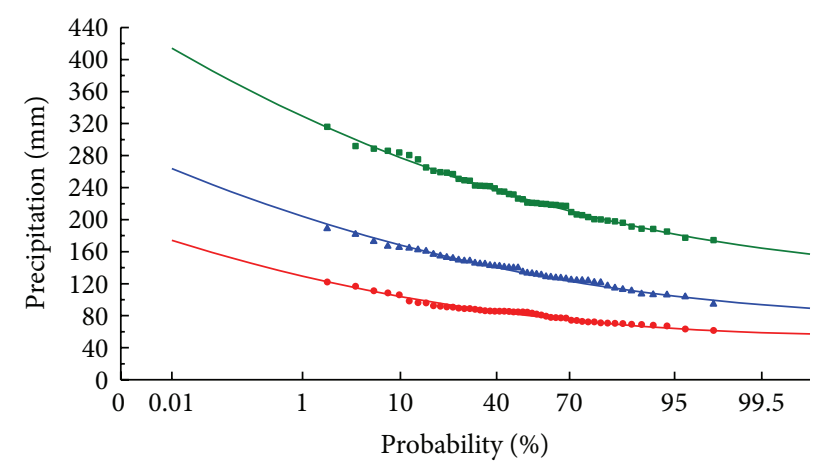

- 15-day maximum precipitation

- 30-day maximum precipitation

- 60-day maximum precipitation

- Frequency curve of 15-day maximum precipitation

- Frequency curve of 30-day maximum precipitation

_ Frequency curve of 60-day maximum precipitation

Figure 4: The frequency curves of 15-day, 30-day, and 60-day maximum rainfall of Tangnaihai basin for the next 50 years.

\subsubsection{Discussion about the Impact of Climate Change on Rainfall Extremes}

(1) Evaluation of Impact of Climate Change on Design Value. To make a comparison between the rainfall extremes of Tangnaihai basin in the measured phase and that in the next 50 years, the two frequency curves were drawn in the same diagram (Figures 5-7).

As shown in Figures 5-7, the frequency curves of annual maximum rainfall in different durations $(15 \mathrm{~d}, 30 \mathrm{~d}$, and $60 \mathrm{~d})$ for the next 50 years are completely higher than that of the measured phase. It indicates that the annual maximum rainfall in different duration would increase with a certain degree due to climate change.

To quantitatively evaluate the impact of climate change on rainfall extreme, the design values of annual maximum in different duration for the measured phase and that for the next 50 year were calculated, and the corresponding results

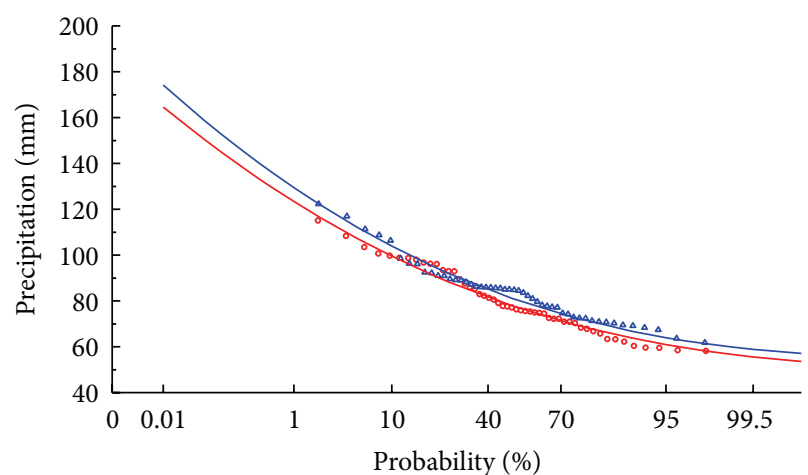

- Observed precipitation

$\triangle \quad$ Predicted precipitation

- Frequency curve for the measured phase

— Frequency curve for the next 50 years

FIGURE 5: Frequency curves of maximum 15-day rainfall of Tangnaihai basin in the measured phase and the next 50 years (2011-2060).

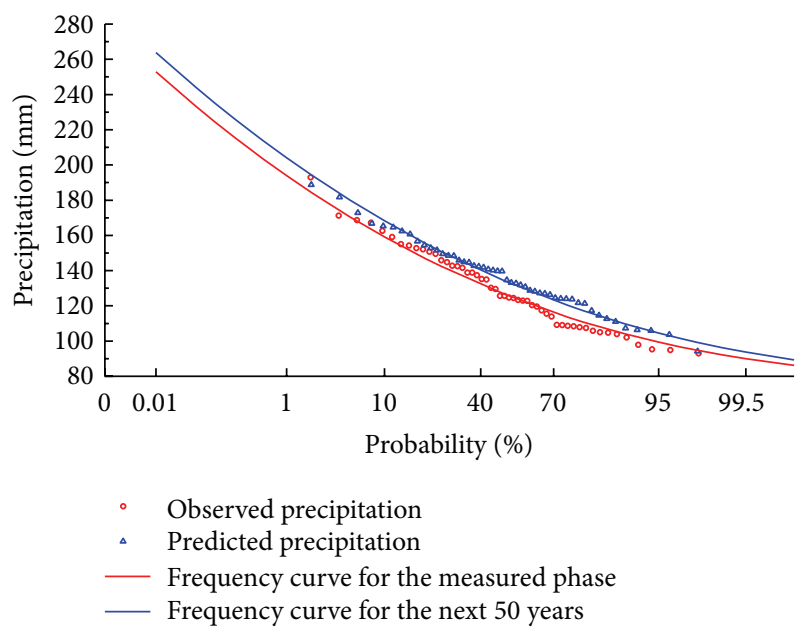

FIGURE 6: Frequency curves of maximum 30-day rainfall of Tangnaihai basin in the measured phase and the next 50 years (2011-2060).

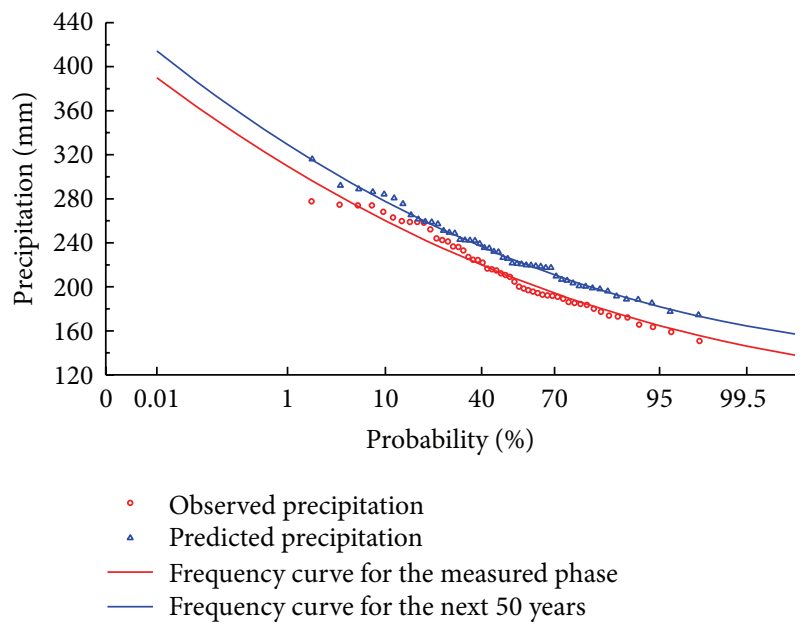

Figure 7: Frequency curves of maximum 60-day rainfall of Tangnaihai basin in the measured phase and the next 50 years (2011-2060). 
TABLE 5: Quantitative evaluation results of impact of climate change on annual rainfall extremes for several given probabilities.

\begin{tabular}{|c|c|c|c|c|c|}
\hline \multirow{2}{*}{ Duration $(d)$} & \multirow{2}{*}{ Items } & \multicolumn{4}{|c|}{ Exceeding probability } \\
\hline & & $1 \%$ & $2 \%$ & $5 \%$ & $10 \%$ \\
\hline \multirow{3}{*}{15} & $\begin{array}{l}\text { Design value of observed } \\
\text { series }(\mathrm{mm})\end{array}$ & 126 & 119 & 110 & 102 \\
\hline & $\begin{array}{l}\text { Design value of forecast } \\
\text { series }(\mathrm{mm})\end{array}$ & 128 & 122 & 113 & 105 \\
\hline & Change rate (\%) & 2 & 2 & 3 & 3 \\
\hline \multirow{3}{*}{30} & $\begin{array}{l}\text { Design value of observed } \\
\text { series }(\mathrm{mm})\end{array}$ & 200 & 190 & 175 & 163 \\
\hline & $\begin{array}{l}\text { Design value of forecast } \\
\text { series }(\mathrm{mm})\end{array}$ & 201 & 192 & 179 & 168 \\
\hline & Change rate (\%) & 1 & 1 & 2 & 3 \\
\hline \multirow{3}{*}{60} & $\begin{array}{l}\text { Design value of observed } \\
\text { series }(\mathrm{mm})\end{array}$ & 316 & 302 & 281 & 264 \\
\hline & $\begin{array}{l}\text { Design value of forecast } \\
\text { series }(\mathrm{mm})\end{array}$ & 332 & 318 & 297 & 280 \\
\hline & Change rate (\%) & 5 & 5 & 6 & 6 \\
\hline
\end{tabular}

are listed in Table 5. As Table 5 shows, the change rates of design of $15 \mathrm{~d}, 30 \mathrm{~d}$, and $60 \mathrm{~d}$ annual maximum rainfall, for the given probabilities ( $1 \%, 2 \%, 5 \%$ and $10 \%)$, are $2 \%-3 \%, 1 \%-3 \%$, and 5\%-6\%, respectively. It indicates that the climate change has impacts on the rainfall extremes in the all durations ( $15 \mathrm{~d}$, $30 \mathrm{~d}$, and $60 \mathrm{~d}$ ) of the Tangnaihai basin, and the change rates vary from $1 \%$ to $6 \%$, but the influence degree of the rainfall extremes in study duration is slight.

(2) Evaluation of Impact of Climate Change on Extreme Events of Given Probabilities. What is the extreme event? There is no universal definition. According to the fourth assessment report of the IPCC [25], the climatic event with occurrence probability $<10 \%$ is defined as the extreme event. Inspired by the IPCC, the hydrologic event with occurrence probability $<10 \%$ is defined as the extreme event in the paper. To quantitatively evaluate the impact of climate change on extreme events, the number of extreme events exceeding the given probabilities $(5 \%, 10 \%$, and $20 \%$ ) can be obtained according to the results of hydrologic frequency analysis and observed or predicted rainfall of different duration (Table 6).

The results of Table 6 show the following:

(1) For 15-day rainfall, 4 extreme events exceed the given probability of $5 \%$ for the next 50 years, accounting for $80 \%$ of extreme events exceeding $5 \%$ in the whole period (measured phase and the next years, 1960-2060), while 8 extreme events exceed the given probability of $10 \%$ for the next 50 years, accounting for $63 \%$ of extreme events exceeding $20 \%$ in the whole period.

(2) For 30-day rainfall, 2 extreme events exceed the given probability of $5 \%$ for the next 50 years, accounting for $67 \%$ of extreme events exceeding $5 \%$ in the whole period, while 11 extreme events exceed the given probability of $10 \%$ for the next 50 years, accounting
TABLE 6: Number of extreme events exceeding given probabilities for the measured phase and the next 50 years.

\begin{tabular}{lcccc}
\hline \multirow{2}{*}{ Duration (d) } & \multirow{2}{*}{ Time range } & \multicolumn{3}{c}{ Exceeding probability } \\
& & $5 \%$ & $10 \%$ & $20 \%$ \\
\hline \multirow{2}{*}{15} & $1960-2010$ & 1 & 3 & 11 \\
& $2011-2060$ & 4 & 5 & 8 \\
\hline \multirow{2}{*}{30} & $1960-2010$ & 1 & 4 & 9 \\
& $2011-2060$ & 2 & 4 & 11 \\
\hline \multirow{2}{*}{60} & $1960-2010$ & 0 & 5 & 11 \\
& $2011-2060$ & 5 & 7 & 13 \\
\hline
\end{tabular}

for $50 \%$ of extreme events exceeding $10 \%$ in the whole period.

(3) For 60-day rainfall, 5 extreme events exceed the given probability of $5 \%$ for the next 50 years, accounting for $100 \%$ of extreme events exceeding $5 \%$ in the whole period, while 13 extreme events exceed the given probability of $10 \%$ for the next 50 years, accounting for $58 \%$ of extreme events exceeding $10 \%$ in the whole period. Generally, the number of extreme events exceeding given probability in the next 50 years is more than that in the measured phase. In other words, the probability of extreme events would increase with different degree in the next 50 years.

On this basis, probability density function of the number of extreme events can be obtained in pattern of the Poisson distribution. Figures 8 and 9 show the diagrams of probability density function of the number of extreme events for the measured phase and the next 50 years. It indicates that the number of extreme events exceeding smaller probability will increase while that exceeding larger probability would decrease. In other words, the extreme events will be more frequent in the next 50 years.

\subsection{Impact of Climate Change on Flood Volume Extreme with Different Durations}

\subsubsection{Model Calibration and Validation}

(1) Model Construction. The Tangnaihai basin was divided into 27 subbasins according to the DEM data; on this basis, the basin was divided into 105 HRUs further according to the land use and soil distribution. The subbasins of the Tangnaihai are shown in Figure 10.

(2) Model Calibration and Validation. In the paper, the observed streamflows for the period of 1995-2004 were used for calibration, and those from 2005 to 2007 were used for the validation of the SWAT model. According to the simulated results of these runoff process mentioned above, the NashSutcliffe coefficient (NS) and deterministic coefficient $\left(R^{2}\right)$ which denote the accuracy of model can be obtained. The NS and $R^{2}$ are 0.76 and 0.80 , respectively, in the calibration period while they are 0.75 and 0.80 , respectively, in the validation period. It indicates that the SWAT model built 

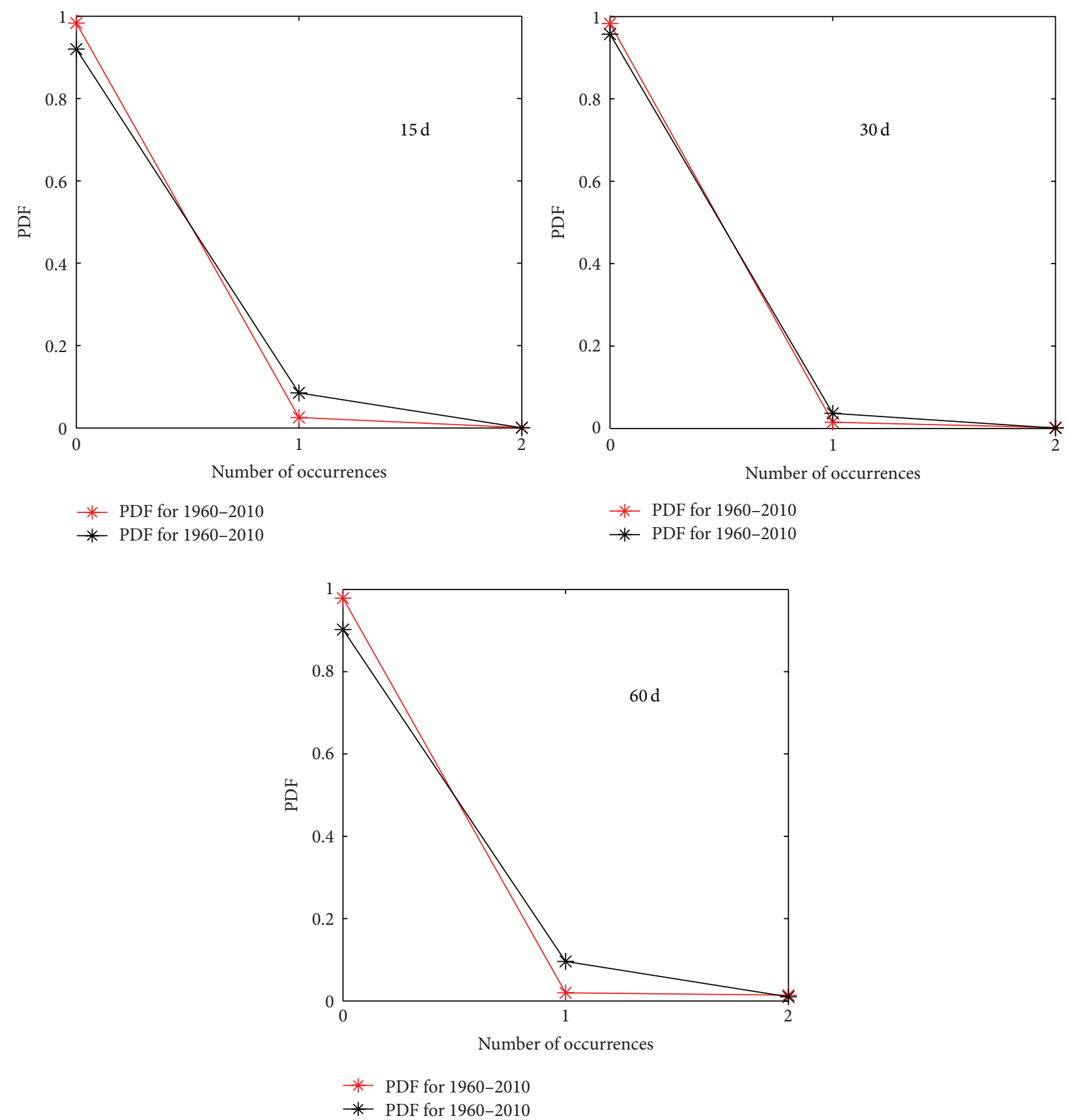

FIGURE 8: Probability density diagram of the precipitation exceeding probability of $5 \%$ for the measured phase and the next 50 years of the Tangnaihai basin.

is of good accuracy and can be adopted to simulate the rainfall-runoff in the study area. Taking several runoff processes as an example, Figures 11 and 12 show the simulation results.

\subsubsection{Design Rainfall in Different Durations Deduced for Next} 50 Years. Long duration rainfall extremes of certain given probabilities $(1 \%, 2 \%, 5 \%$, and $10 \%)$ of the Tangnaihai basin for the next 50 years were deduced in Section 4.2.2. However, the results are not enough to meet the requirements for deducing long duration flood volume extremes by SWAT, and the design rainfall process is also needed. Therefore, the design rainfall process should be deduced firstly.

The basic idea and procedure to deduce design rainfall process in different given probabilities are as follows: (1) selecting one typical storm process with certain principles; (2) magnifying it according to the design rainfall value and keeping the maximum rainfall of given duration and probability of magnified typical storm process equal to the design rainfall of corresponding duration and probability. In the paper, the storm process that occurred from 28/5/1989 to $26 / 7 / 1989$ was selected as the typical storm. According to 

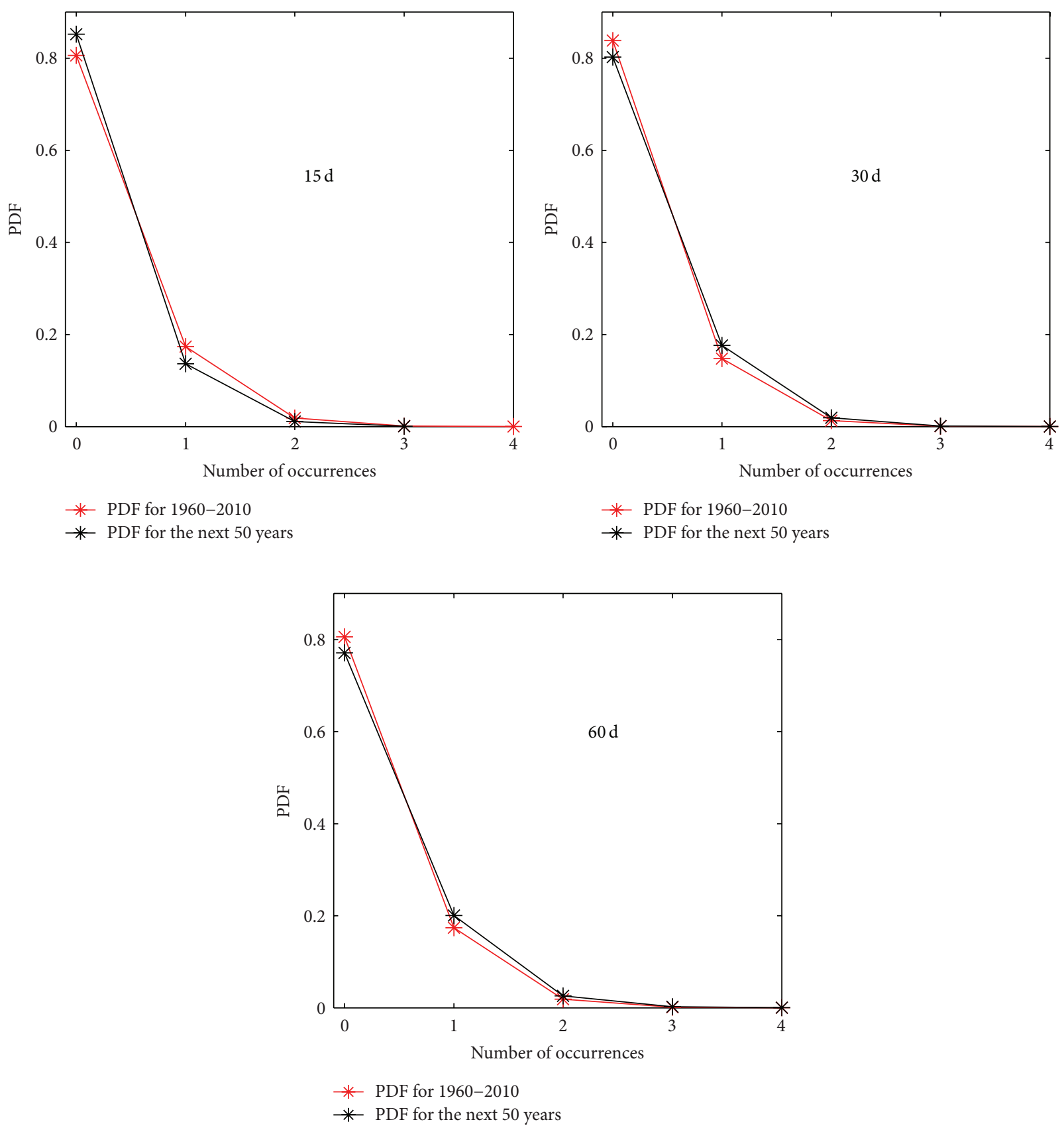

FIGURE 9: Probability density diagram of the rainfall extreme event exceeding probability of $20 \%$ for the measured phase and the next 50 years of Tangnaihai basin.

the magnified method, design rainfall process of different return periods (100 a, $50 \mathrm{a}, 20 \mathrm{a}$, and $10 \mathrm{a})$ can be obtained. Taking return period of $100 \mathrm{a}$ as an example, Figure 13 shows the process of rainfall.

Similarly, design rainfall process of different return periods (100 a, 50 a, 20 a, and 10 a) for the measured phase can be obtained. Taking return period of $100 \mathrm{a}$ as an example, Figure 14 shows the process of rainfall.

4.3.3. Design Flood Volume in Different Durations Deduced for Next 50 Years. According to the design rainfall process of given probability, the flood hydrography of corresponding probability was deduced, respectively, by running the SWAT. On this basis, the long duration flood volume of different probabilities for the next 50 years can be obtained. The results are listed in Table 7.

4.3.4. Discussion on Impact of Climate Change on Flood Volume Extreme. Taking the design rainfall process in different probability as input condition for SWAT, the design flood process in corresponding probability can be obtained by running the model. In the paper, design flood process of 


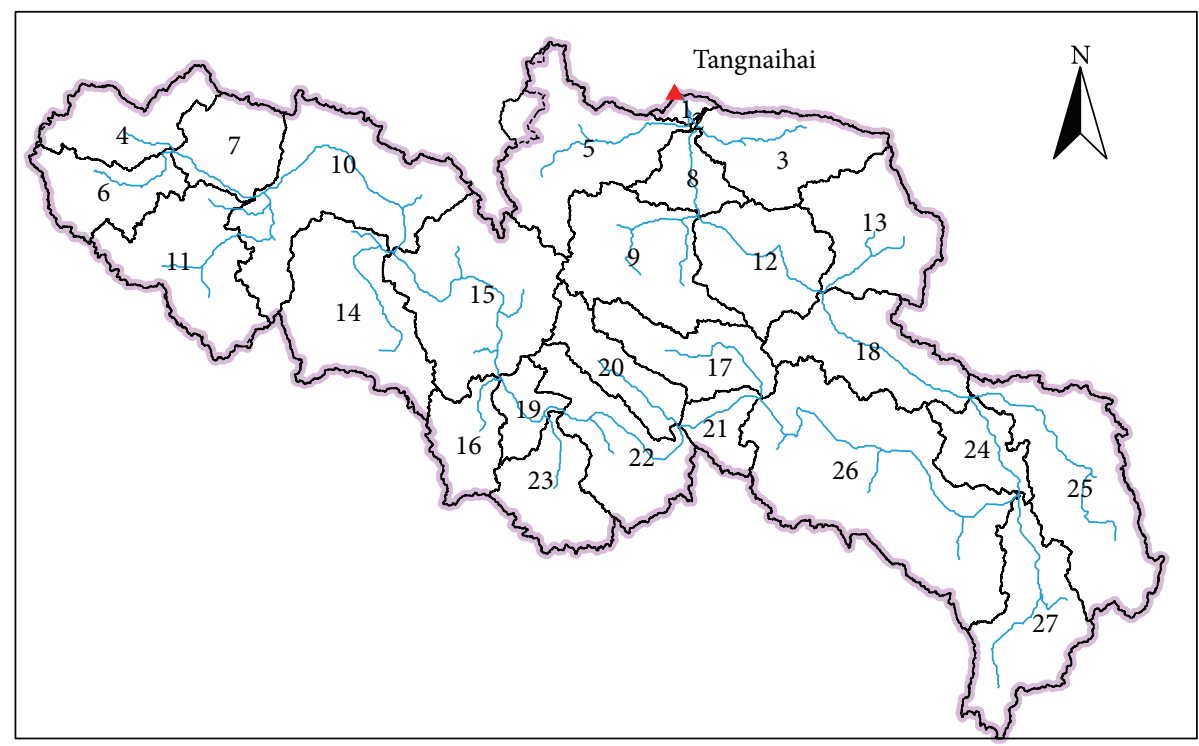

$\Delta$ Outlet

River

Subbasin

FIgURE 10: Subbasins of Tangnaihai basin.

TABLE 7: Long duration flood volume of different probabilities for the next 50 years of Tangnaihai basin.

\begin{tabular}{lcccc}
\hline \multirow{2}{*}{ Duration (d) } & \multicolumn{4}{c}{ Return period (a) } \\
& 100 & 50 & 20 & 10 \\
\hline 15 & 126 & 119 & 110 & 102 \\
30 & 200 & 190 & 175 & 163 \\
60 & 316 & 302 & 281 & 264 \\
\hline
\end{tabular}

TABLE 8: Change rates of design flood volume in different durations of given probabilities (\%).

\begin{tabular}{lcccc}
\hline Duration (d) & \multicolumn{4}{c}{ Return period (a) } \\
& 100 & 50 & 20 & 10 \\
\hline 15 & 3 & 3 & 3 & 1 \\
30 & 3 & 2 & 3 & 1 \\
60 & 3 & 5 & 6 & 5 \\
\hline
\end{tabular}

different return period including 100 a, 50 a, 20 a, and 10 a was simulated. Figures 15-18 show the design hydrographs which are of four return periods (100 a, $50 \mathrm{a}, 20 \mathrm{a}$, and $10 \mathrm{a}$ ) for the measured phase and the next 50 years, respectively.

According to Figures 15-18, it is obvious that the design flood hydrograph is higher for the next 50 years than that of the measured phase. It indicates that the flood volume extremes show an increasing trend in the Tangnaihai basin. To take a close investigation into the rising trend and make a quantitative estimation, change rates of flood volume in different durations of four kinds of probabilities (1\%, $2 \%, 5 \%$, and $10 \%)$ are calculated and listed in Table 8.

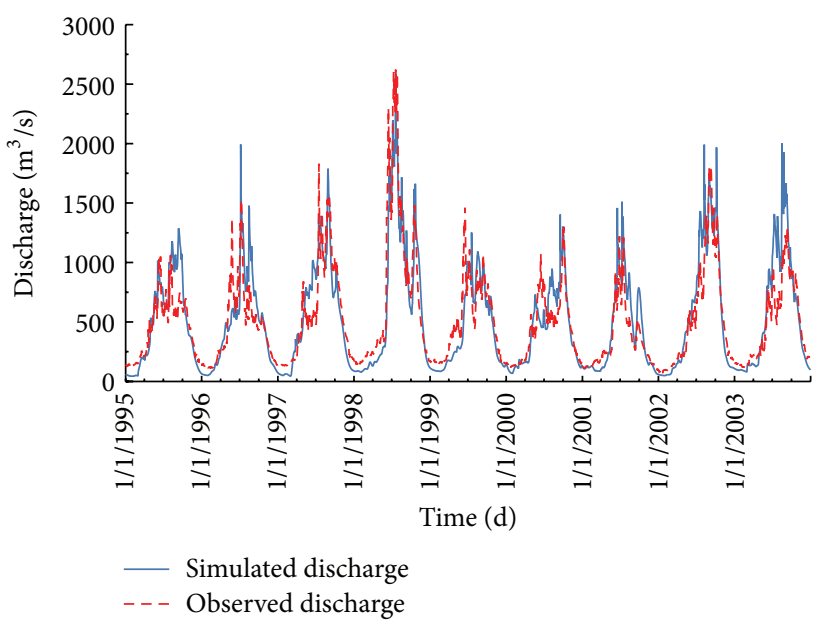

FIGURE 11: Observed and simulated hydrographs of Tangnaihai cross section in calibration period.

According to Table 8, the increasing rates of 15-day flood volume for different return period vary from $1 \%$ to $3 \%$; the increasing rates of 30-day flood volume for different return period vary from $1 \%$ to $3 \%$; and the increasing rates of 60-day flood volume for different return period vary from $3 \%$ to $6 \%$. It indicates that the increasing rates of long duration flood volume of Tangnaihai basin is less than $10 \%$. In other words, the flood volume extremes in long duration of Tangnaihai basin increase slightly in the next 50 years. 


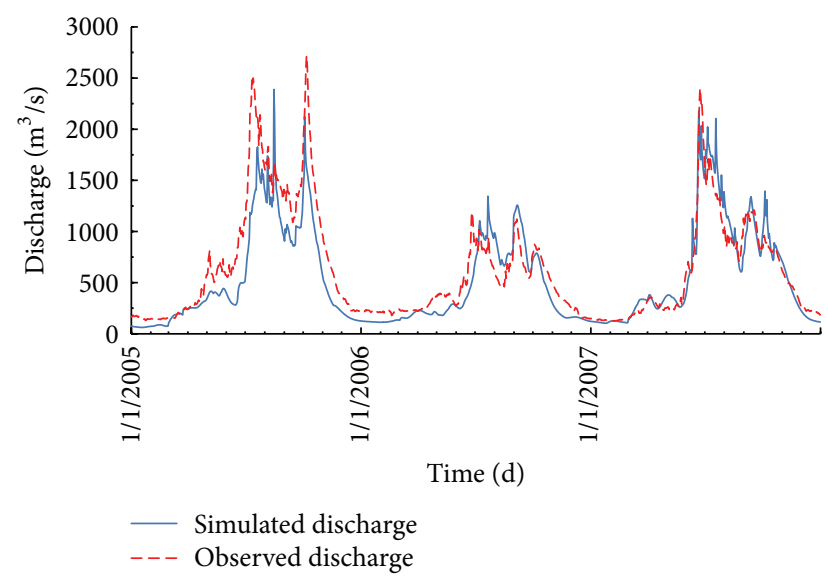

FIgURE 12: Observed and simulated hydrographs of Tangnaihai cross section in validation period.

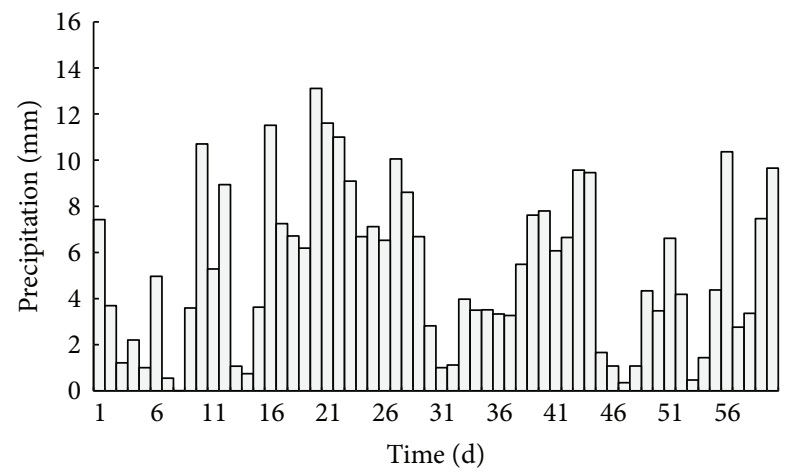

FIGURE 13: The process of 100-year design rainfall of Tangnaihai basin for the next 50 years.

\section{Conclusions}

To study the impact of climate change on hydrologic extremes in the Tangnaihai basin which locates in the upstream of Yellow River, the BCC-CSM-1.1 released by IPCC 5 was used to forecast rainfall in the next 50 years (2011-2060). On this basis, according to the observed hydrologic data series, the evolution law of long duration hydrologic extremes of Tangnaihai basin is revealed. Main conclusions can be achieved as follows.

(1) It indicates that the values of long duration (15 d, $30 \mathrm{~d}$, and $60 \mathrm{~d}$ ) rainfall extremes of Tangnaihai basin will rise by slightly increasing rate in the next 50 years. According to analysis results of rainfall extremes in different durations, 15 -day design rainfall of given probabilities $(1 \%, 2 \%, 5 \%$, and $10 \%)$ will increase by $2 \%-3 \%$; similarly, 30-day design rainfall will increase by $1 \%-3 \%$ and 60 -day design rainfall will increase by $5 \%-6 \%$, respectively. It is obvious that the increasing rates of rainfall extremes in given probabilities are less than $10 \%$; in other words, the rainfall extremes of the Tangnaihai basin would increase with a slight degree.

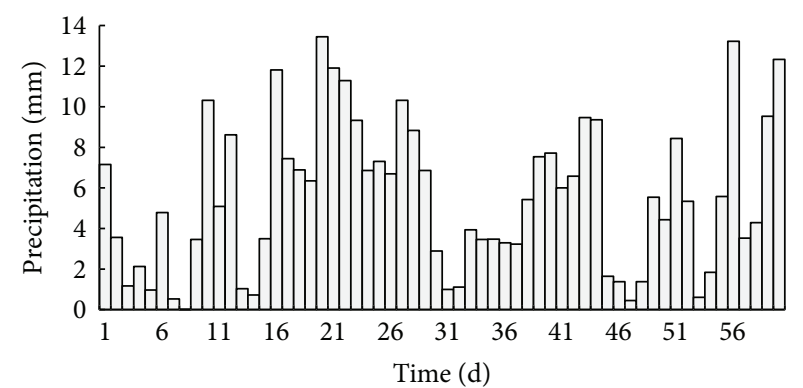

FIGURE 14: The process of 100-year design rainfall of Tangnaihai basin for the measured phase.

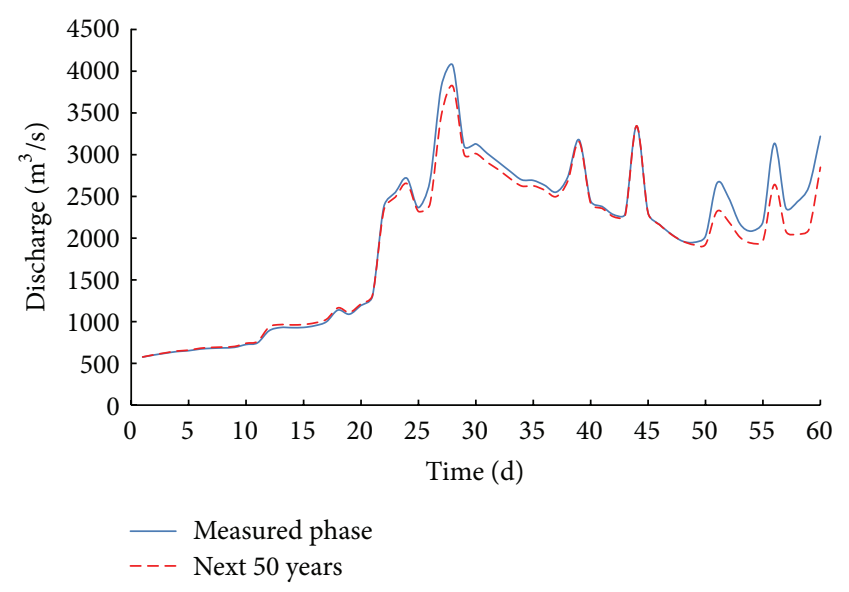

FIGURE 15: 100-year flood hydrograph for the measured phase and the next 50 years of Tangnaihai basin.

(2) It indicates that the number of extreme events exceeding smaller probability will increase for the next 50 years. According to the analysis of number of extreme events exceeding given probability, it is obvious that the extreme events of long duration rainfall exceeding given probabilities $(5 \%, 10 \%$, and $20 \%)$ will get more frequent.

(3) It indicates that the values of long duration (15d, $30 \mathrm{~d}$, and $60 \mathrm{~d}$ ) flood volume extremes of Tangnaihai basin will rise by slightly increasing rate in the next 50 years. On the hypothesis that rainfall of given frequency could generate the flood of the same frequency, SWAT model was used to deduce design flood with the import of design rainfall for the next 50 years, and the long flood volume extremes were achieved. According to the analysis of results of flood volume extremes in different duration, 15-day design flood volume of given probabilities $(1 \%, 2 \%, 5 \%$, and $10 \%$ ) is increasing by $1 \%-3 \%$ based on BCC-CSM-1.1; similarly, 30-day design flood volume is increasing by $1 \%-3 \%$ and 60 -day design flood volume is increasing by $3 \%-6 \%$, respectively. It obvious that the increasing rate of flood volume extremes in given probability is less than $10 \%$, in other words, the flood volume 


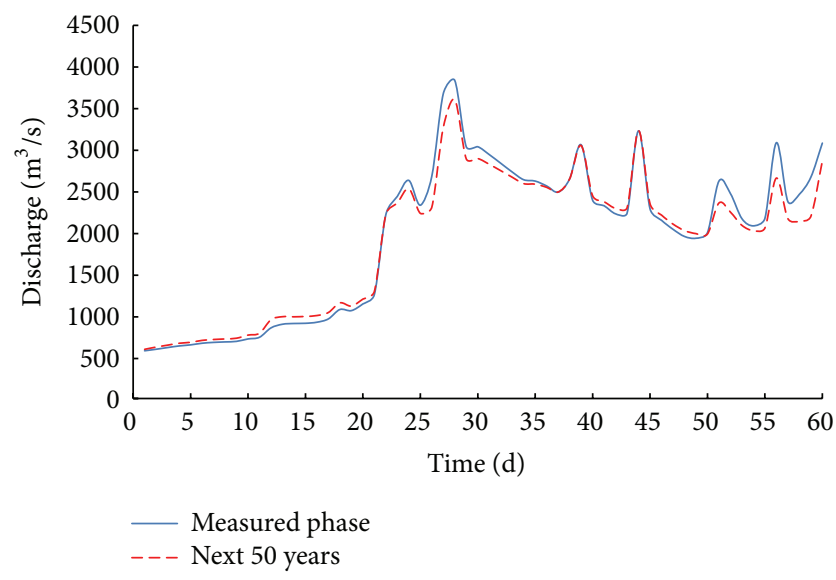

Figure 16: 50-year flood hydrograph for the measured phase and the next 50 years of Tangnaihai basin.

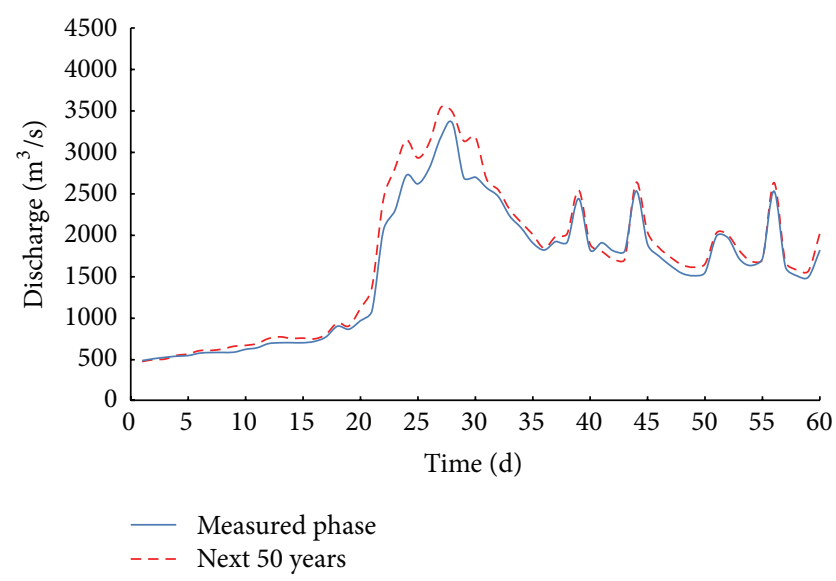

FIGURE 17: 20-year flood hydrograph for the measured phase and the next 50 years of Tangnaihai basin.

extremes of the Tangnaihai basin would increase with a slight degree.

Generally, the long duration hydrologic extremes of the Tangnaihai basin in Yellow River basin would increase by a slight degree in the next 50 years. The conclusions were addressed on the basis of BCC-CSM-1.1. However, if several more suitable climate change model products were adopted, the conclusions on impact of climate change in study area will be more reliable. To improve the study, we will try more GCM outputs and continue in-depth studies on the same theme in the future.

\section{Competing Interests}

The authors declare that there are no competing interests regarding the publication of this paper.

\section{Authors' Contributions}

The studies were designed by Jun Wang, Zhongmin Liang, Dong Wang, Tian Liu, and Jing Yang. Specifically, Jun Wang

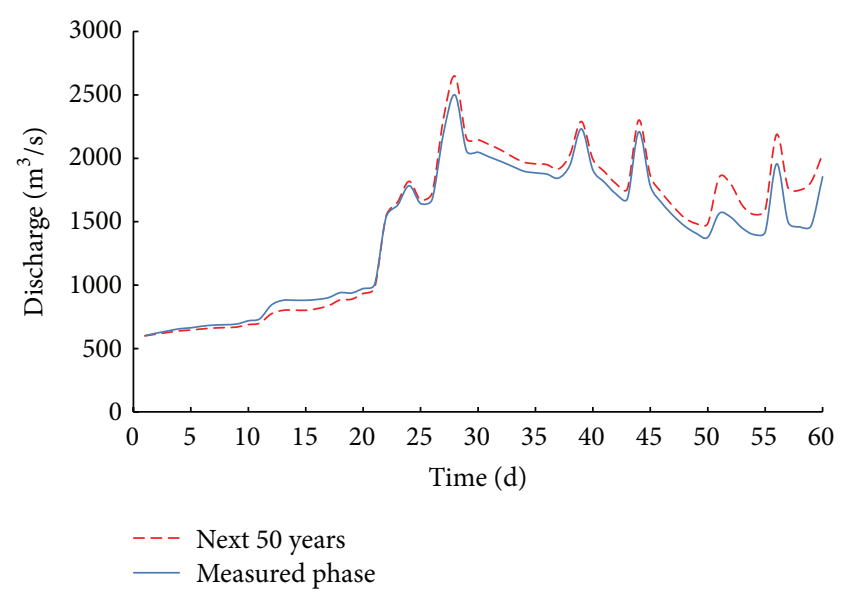

FIGURE 18: 10-year flood hydrograph for the measured phase and the next 50 years of Tangnaihai basin.

and Zhongmin Liang performed the studies and analyzed the data, Dong Wang processed the precipitation simulated by climate model, Tian Liu built the SWAT model and calculated design flood, and Jing Yang helped to hydrologic frequency analysis and helped refine the charts and polish the paper.

\section{Acknowledgments}

This study was supported by the Public Welfare Industry Special Fund Project of Ministry of Water Resources of China (nos. 201301066 and 201401034), the National Natural Science Foundation of China (nos. 51109054, 51179046, and 51479061), National Science and Technology Support Plan (no. 2013BAB06B01), and Excellent Ph.D. Training program (no. 2015B05514).

\section{References}

[1] N. S. Christensen, A. W. Wood, N. Voisin, D. P. Lettenmaier, and R. N. Palmer, "The effects of climate change on the hydrology and water resources of the Colorado River basin," Climatic Change, vol. 62, no. 1-3, pp. 337-363, 2004.

[2] M. K. Jha and P. W. Gassman, "Changes in hydrology and streamflow as predicted by a modelling experiment forced with climate models," Hydrological Processes, vol. 28, no. 5, pp. 27722781, 2014.

[3] C. Yang, Z. Yu, Z. Hao, J. Zhang, and J. Zhu, "Impact of climate change on flood and drought events in Huaihe River Basin, China," Hydrology Research, vol. 43, no. 1-2, pp. 14-22, 2012.

[4] Z. Yu, T. Yang, and F. W. Schwartz, "Water issues and prospects for hydrological science in China," Water Science and Engineering, vol. 7, no. 1, pp. 1-4, 2014.

[5] A. C. Horrevoets, H. H. G. Savenije, J. N. Schuurman, and S. Graas, "The influence of river discharge on tidal damping in alluvial estuaries," Journal of Hydrology, vol. 294, no. 4, pp. 213228, 2004.

[6] N. L. Poff, J. D. Allan, M. B. Bain et al., "The natural flow regime: a paradigm for river conservation and restoration," BioScience, vol. 47, no. 11, pp. 769-784, 1997. 
[7] N. Y. Krakauer and I. Fung, "Mapping and attribution of change in streamflow in the coterminous United States," Hydrology and Earth System Sciences, vol. 12, no. 4, pp. 1111-1120, 2008.

[8] K. Stahl, H. Hisdal, J. Hannaford et al., "Streamflow trends in Europe: evidence from a dataset of near-natural catchments," Hydrology and Earth System Sciences, vol. 14, no. 12, pp. 23672382, 2010.

[9] F. H. S. Chiew, J. Teng, J. Vaze et al., "Estimating climate change impact on runoff across southeast Australia: method, results, and implications of the modeling method," Water Resources Research, vol. 45, no. 10, Article ID W10414, 2009.

[10] A. Senatore, G. Mendicino, G. Smiatek, and H. Kunstmann, "Regional climate change projections and hydrological impact analysis for a Mediterranean basin in Southern Italy," Journal of Hydrology, vol. 399, no. 1-2, pp. 70-92, 2011.

[11] M. V. Shabalova, W. P. A. Van Deursen, and T. A. Buishand, "Assessing future discharge of the river Rhine using regional climate model integrations and a hydrological model," Climate Research, vol. 23, no. 3, pp. 233-246, 2003.

[12] Q. Liu and B. Cui, "Impacts of climate change/variability on the streamflow in the Yellow River Basin, China," Ecological Modelling, vol. 222, no. 2, pp. 268-274, 2011.

[13] C. Cunnane, "Statistical distribution for flood frequency analysis," Operational Hydrology Report (WMO) 781, 1989.

[14] D. R. Maidment, Handbook of Hydrology, McGraw-Hill, New York, NY, USA, 1992.

[15] Z. M. Liang, Hydrologic Analysis and Calculation, China Water Power Press, 2013.

[16] Y. F. Chen, Ed., Engineering Hydrology and Flood Control Calculation and Water Resources Analysis, China Water \& Power Press, 2013.

[17] J. G. Arnold, R. Srinivasan, R. S. Muttiah, and J. R. Williams, "Large area hydrologic modeling and assessment part I: model development," Journal of the American Water Resources Association, vol. 34, no. 1, pp. 73-89, 1998.

[18] S. L. Neitsch, J. G. Arnold, J. R. Kiniry, and J. R. Williams, SWAT User Manual, Version 2005, Grassland Soil and Water Research Laboratory, Temple, Tex, USA, 2005.

[19] J. G. Arnold, J. R. Kiniry, R. Srinivasan, J. R. Williams, E. B. Haney, and S. L. Neitsch, SWAT Input/Output File Documentation, Version 2009, Grassland Soil and Water Research Laboratory, Temple, Tex, USA, 2011.

[20] S. L. Neitsch, J. G. Arnold, J. R. Kiniry, and J. R. Williams, "SWAT user manual, version 2009," Texas Water Resources Institute Technical Report, Texas A\&M University, College Station, Tex, USA, 2011.

[21] USDA Soil Conservation Service, National Engineering Handbook. Hydrology Section 4, chapter 4-10, 1972.

[22] S. Bergström, B. Carlsson, M. Gardelin, G. Lindström, A. Pettersson, and M. Rummukainen, "Climate change impacts on runoff in Sweden assessments by global climate models, dynamical down-scaling and hydrological modelling," Climate Research, vol. 16, pp. 101-112, 2001.

[23] L. P. Graham, J. Andreáasson, and B. Carlsson, "Assessing climate change impacts on hydrology from an ensemble of regional climate models, model scales and linking methodsa case study on the Lule River basin," Climatic Change, vol. 81, no. 1, pp. 293-307, 2007.

[24] C. Teutschbein and J. Seibert, "Bias correction of regional climate model simulations for hydrological climate-change impact studies: review and evaluation of different methods," Journal of Hydrology, vol. 456-457, pp. 12-29, 2012.
[25] IPCC, Climate Change 2007: The Physical Basis. Contribution of Working Group1 to the Fouth Assessment Report of the IPCC, Cambridge University Press, New York, NY, USA, 2007. 

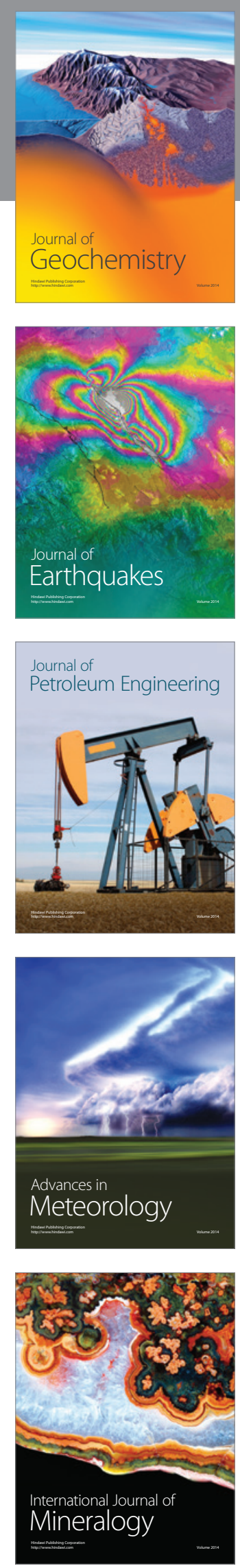
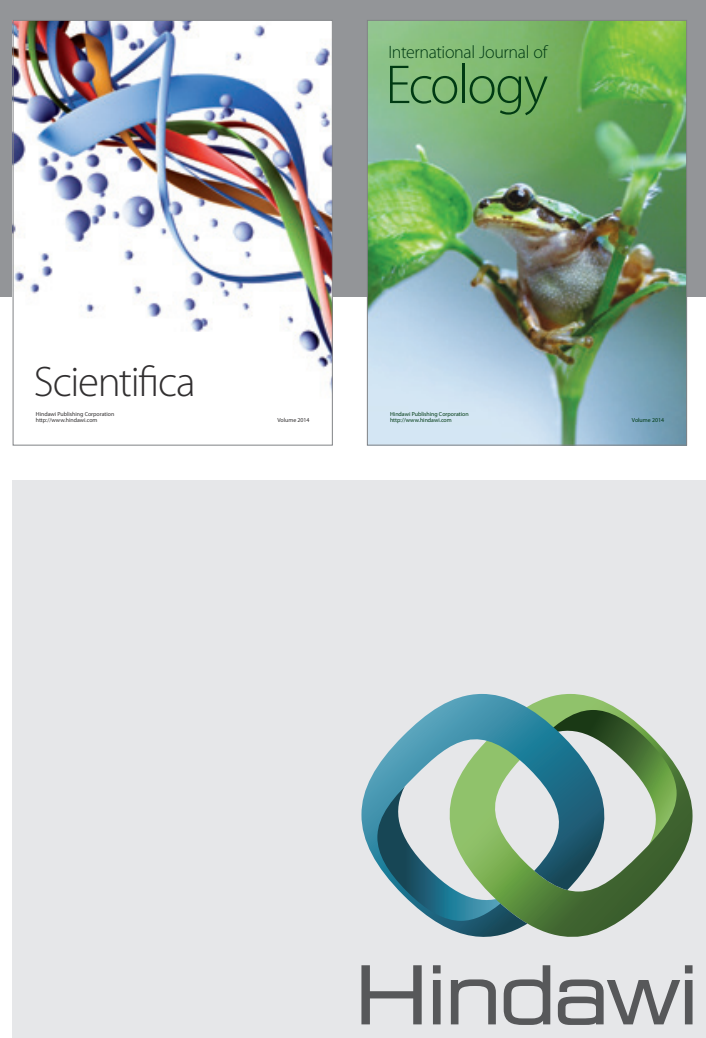

Submit your manuscripts at

http://www.hindawi.com
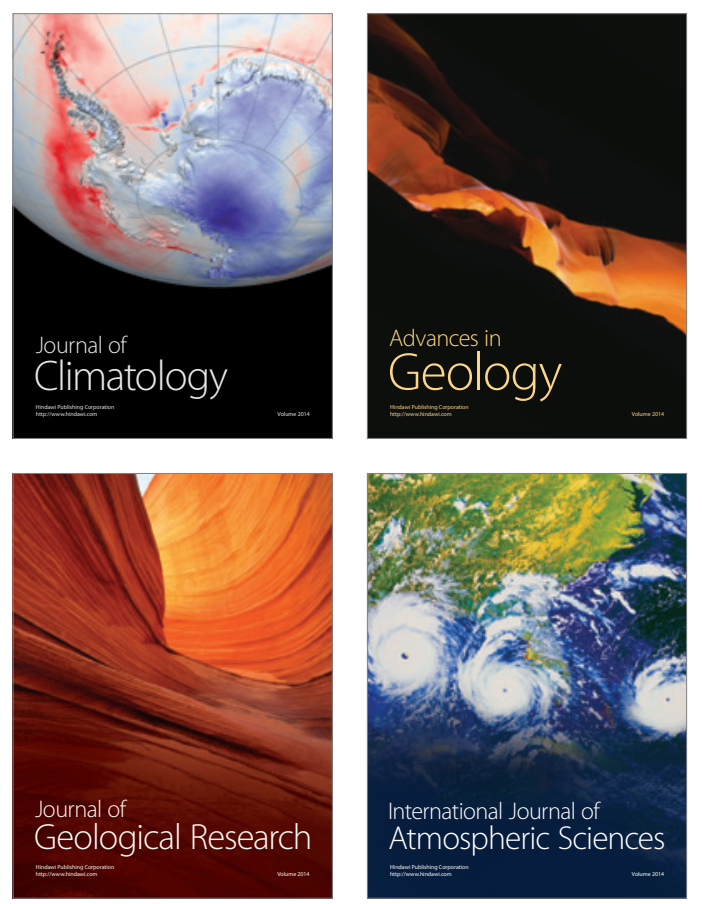

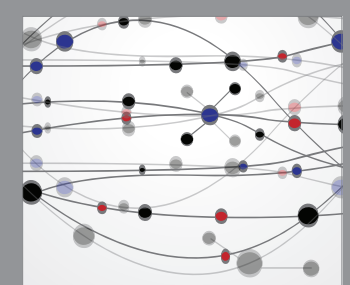

The Scientific

\section{World Journal}
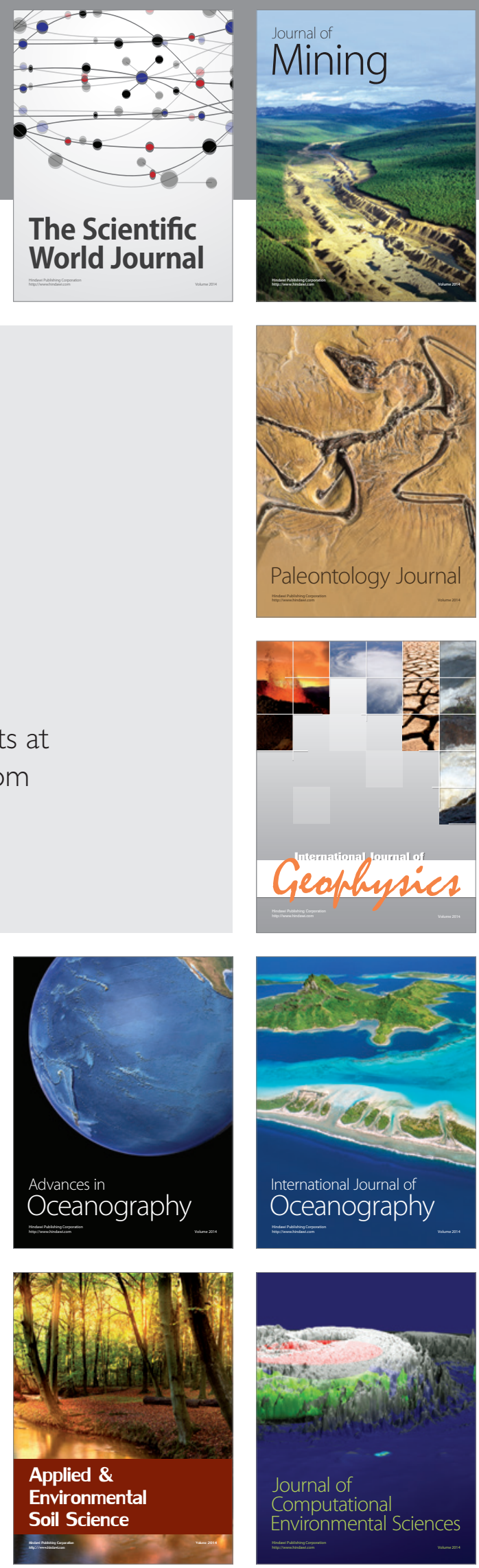